\title{
Covalent Cross-Linking as an Enabler for Structural Mass
}

\section{Spectrometry}

Emeline Hanozin, ${ }^{1}$ Elodie Grifnée, ${ }^{1}$ Hugo Gattuso, ${ }^{2}$ André Matagne, ${ }^{3}$ Denis Morsa, ${ }^{1}$ Edwin

De Pauw ${ }^{1, *}$

${ }^{1}$ Mass Spectrometry Laboratory, Molsys Research Unit, University of Liège, B-4000 Liège, Belgium

${ }^{2}$ Theoretical Physical Chemistry, Molsys Research Unit, University of Liège, B-4000 Liège, Belgium

${ }^{3}$ Laboratory of Enzymology and Protein Folding, Center for Protein Engineering, University of Liège, B-4000 Liège, Belgium

*Corresponding author: e.depauw@uliege.be

\section{Table of contents}

Table S1. Synapt G2-Si HDMS (Waters) - Instrument default setup... S-2

Table S2. timsTOF (Bruker) - Instrument default setup. S-3

Table S3. Synapt G2-Si HDMS (Waters) - List of calibrants.. S-4

Figure S1. Synapt G2-Si HDMS (Waters) - Ion mobility calibration. S-5

Figure S2. Representation of the heme group and BS3 cross-linker and force field parametrization. S-6

Figure S3. CL/ML products for $\beta$-lactoglobulin $(z=+9)$ and myoglobin $(z=+9)$. S-8

Figure S4. CSDs of (non-)cross-linked $\beta$-lactoglobulin and myoglobin. S-9

Figure S5. ${ }^{\mathrm{TW}} \mathrm{CCS}_{\mathrm{N} 2} \rightarrow \mathrm{He}$ distributions of $\beta$-lactoglobulin $(z=+9)$ and myoglobin $(z=+9)$. S-10

Figure S6. Positions of the $\mathrm{BS}^{3}$ linkers on the starting geometry of cytochrome $c$ used for MD. ....S-11

Table S4. List of the reported $\mathrm{BS}^{3}$ cross-linked residues for cytochrome $c$. S-11

Figure S7. Positions of the electric charges on the initial geometry of cytochrome $c$ used for MD. S-12

Table S5. List of the positions of the electric charges on the initial geometry of cytochrome $c$ used for MD. S-12

Figure S8. ${ }^{\mathrm{TW}} \mathrm{CCS}_{\mathrm{N} 2} \rightarrow \mathrm{He}$ distributions of cytochrome $c$ carrying from $0 \mathrm{ML}$ to $3 \mathrm{ML}$ S-13 
Table S1. Synapt G2-Si HDMS (Waters) - Instrument default setup.

\begin{tabular}{|c|c|}
\hline Capillary (ESI) & $1.6 \mathrm{kV}$ \\
\hline Sampling cone & $5 \mathrm{~V}$ \\
\hline Source offset & $1 \mathrm{~V}$ \\
\hline Source temperature & $80^{\circ} \mathrm{C}$ \\
\hline Desolvation temperature & $100^{\circ} \mathrm{C}$ \\
\hline Cone gas flow & $50{\mathrm{~L} . \mathrm{h}^{-1}}^{1}$ \\
\hline Desolvation gas flow & 500 L.h $^{-1}$ \\
\hline Nebulizer & 3 bar \\
\hline Trap collision energy & $2 \mathrm{~V}$ \\
\hline Transfer collision energy & $2 \mathrm{~V}$ \\
\hline Trap/transfer gas pressure (Ar) & $2.2 \times 10^{-2} \mathrm{mbar}\left(2 \mathrm{~mL} \cdot \mathrm{min}^{-1}\right)$ \\
\hline He cell gas pressure $(\mathrm{He})$ & $3.4 \mathrm{mbar}\left(180 \mathrm{~mL} \cdot \mathrm{min}^{-1}\right)$ \\
\hline IM cell gas pressure $\left(\mathrm{N}_{2}\right)$ & $2.75 \mathrm{mbar}\left(90 \mathrm{~mL} \cdot \mathrm{min}^{-1}\right)$ \\
\hline Trap DC entrance & $3 \mathrm{~V}$ \\
\hline Trap DC bias & $35 \mathrm{~V}-100 \mathrm{~V}$ \\
\hline Trap DC exit & $0 \mathrm{~V}$ \\
\hline IMS DC Entrance & $20 \mathrm{~V}$ \\
\hline He Cell DC & $50 \mathrm{~V}$ \\
\hline He Exit & $20 \mathrm{~V}$ \\
\hline IMS DC Bias & $3 \mathrm{~V}$ \\
\hline IMS DC exit & $0 \mathrm{~V}$ \\
\hline Transfer DC entrance & $5 \mathrm{~V}$ \\
\hline Transfer DC exit & $15 \mathrm{~V}$ \\
\hline IM wave speed & $1000 \mathrm{~m} \cdot \mathrm{s}^{-1}$ \\
\hline IM wave height & $40 \mathrm{~V}$ \\
\hline Trap wave speed & $311 \mathrm{~m} \cdot \mathrm{s}^{-1}$ \\
\hline Trap wave height & $4 \mathrm{~V}$ \\
\hline Transfer wave speed & $380 \mathrm{~m} \cdot \mathrm{s}^{-1}$ \\
\hline Transfer wave height & $4 \mathrm{~V}$ \\
\hline
\end{tabular}


Table S2. timsTOF (Bruker) - Instrument default setup.

\begin{tabular}{|l|l|}
\hline Capillary (ESI) & $4.5 \mathrm{kV}$ \\
\hline End Plate Offset & $2.5 \mathrm{kV}$ \\
\hline Dry gas & $8 \mathrm{~L} / \mathrm{min}$ \\
\hline Dry temp & $220^{\circ} \mathrm{C}$ \\
\hline$\Delta 1$ & $-20 \mathrm{~V}$ \\
\hline$\Delta 2$ & $-270 \mathrm{~V}$ \\
\hline$\Delta 3$ & $18 \mathrm{~V}$ \\
\hline$\Delta 4$ & $250 \mathrm{~V}$ \\
\hline$\Delta 5$ & $0 \mathrm{~V}$ \\
\hline$\Delta 6$ & $70 \mathrm{~V}$ \\
\hline Funnel $1 / 2$ RF & $300 \mathrm{Vpp}$ \\
\hline Collision Energy & $10 \mathrm{eV}$ \\
\hline $1 / \mathrm{K}_{0}$ start & $0.71 \mathrm{~V} . \mathrm{s} / \mathrm{cm}^{2}$ \\
\hline $1 / \mathrm{K}_{0}$ end & $1.78 \mathrm{~V} . \mathrm{s} / \mathrm{cm}^{2}$ \\
\hline Ramp Time & $300 \mathrm{~ms}$ \\
\hline Accumulation Time & $20 \mathrm{~ms}-300 \mathrm{~ms}$ \\
\hline Tunnel In & $2.57 \mathrm{mbar}$ \\
\hline Tunnel Out & $8.06 \times 10^{-1} \mathrm{mbar}$ \\
\hline
\end{tabular}


Table S3. Synapt G2-Si HDMS (Waters) - List of calibrants.

\begin{tabular}{|c|c|c|c|c|}
\hline Molecule & $\mathbf{z}$ & $\mathbf{m}$ & $\mathbf{m} / \mathbf{z}$ & $\mathbf{\Omega}(\mathrm{He})$ \\
\hline LVVSTQTALA & 2 & 1001.6 & 501.8 & 237 \\
\hline QTALVELLK & 2 & 1013.6 & 507.8 & 243 \\
\hline HLVDEPQNLIK & 2 & 1304.7 & 653.4 & 284 \\
\hline TVMENFVAFVDK & 2 & 1398.8 & 700.4 & 298 \\
\hline SLHTLFGDELCK+CAM & 2 & 1418.8 & 710.4 & 297 \\
\hline YICDNQDTISSK+CAM & 2 & 1442.6 & 722.3 & 294 \\
\hline LGEYGFQNALIVR & 2 & 1478.8 & 740.4 & 306 \\
\hline DDPHACYSTVFDK+CAM & 2 & 1553.6 & 777.8 & 310 \\
\hline MPCTEDYLSLILNR+CAM & 2 & 1723.8 & 862.9 & 337 \\
\hline YNGVFQECCQAEDK+CAM & 2 & 1746.8 & 874.4 & 318 \\
\hline DDPHACYSTVFDK+CAM & 3 & 1553.7 & 518.9 & 321 \\
\hline KVPQVSTPTLVEVSR & 3 & 1638.9 & 547.3 & 335 \\
\hline DAFLGSFLYEYSRR & 3 & 1722.9 & 575.3 & 372 \\
\hline DAIPENLPPLTADFAEDKDVCK+CAM & 3 & 2457.3 & 820.1 & 429 \\
\hline Ubiquitin $^{(\mathrm{b})}$ & 7 & 8568 & 1225 & 1580 \\
\hline Ubiquitin & 8 & 8568 & 1072 & 1622 \\
\hline Ubiquitin & 9 & 8568 & 953 & 1649 \\
\hline Ubiquitin & 10 & 8568 & 858 & 1732 \\
\hline Ubiquitin & 11 & 8568 & 778 & 1802 \\
\hline Bradykinin $^{(\mathrm{d})}$ & 1 & 1059 & 1060 & 245 \\
\hline Myoglobin (equine) ${ }^{(\mathrm{e})}$ & 13 & 16952 & 1305 & 3136 \\
\hline Myoglobin (equine) & 14 & 16952 & 1212 & 3143 \\
\hline Myoglobin (equine) & 15 & 16952 & 1131 & 3230 \\
\hline Myoglobin (equine) & 16 & 16952 & 1061 & 3313 \\
\hline Myoglobin (equine) & 17 & 16952 & 998 & 3384 \\
\hline Myoglobin (equine) & 18 & 16952 & 943 & 3489 \\
\hline Myoglobin (equine) & 19 & 16952 & 893 & 3570 \\
\hline Myoglobin (equine) & 20 & 16952 & 849 & 3682 \\
\hline Myoglobin (equine) & 21 & 16952 & 808 & 3792 \\
\hline Myoglobin (equine) & 22 & 16952 & 772 & 3815 \\
\hline
\end{tabular}

(a) Bush, M. F., Campuzano, I. D. G. \& Robinson, C. V. Ion mobility mass spectrometry of peptide ions: Effects of drift gas and calibration strategies. Anal. Chem. 84, 7124-7130 (2012).

(b) Valentine, S. J., Counterman, A. E. \& Clemmer, D. E. Conformer-dependent proton-transfer reactions of ubiquitin ions. Journal of the American Society for Mass Spectrometry 8, 954-961 (1997).

(c) Chen, Y. L., Collings, B. a. \& Douglas, D. J. Collision cross sections of myoglobin and cytochrome c ions with Ne, Ar, and Kr. J. Am. Soc. Mass Spectrom. 8, 681-687 (1997).

(d) Counterman, a. E. et al. High-order structure and dissociation of gaseous peptide aggregates that are hidden in mass spectra. J. Am. Soc. Mass Spectrom. 9, 743-759 (1998).

(e) Shelimov, K. B. \& Jarrold, M. F. Conformations, unfolding, and refolding of apomyoglobin in vacuum: An activation barrier for gas-phase protein folding. J. Am. Chem. Soc. 119, 2987-2994 (1997). 
Figure S1. Synapt G2-Si HDMS (Waters) - Ion mobility calibration.

Calibration curve to convert arrival time $t_{d}$ measured in nitrogen into collision cross section $\Omega$ :

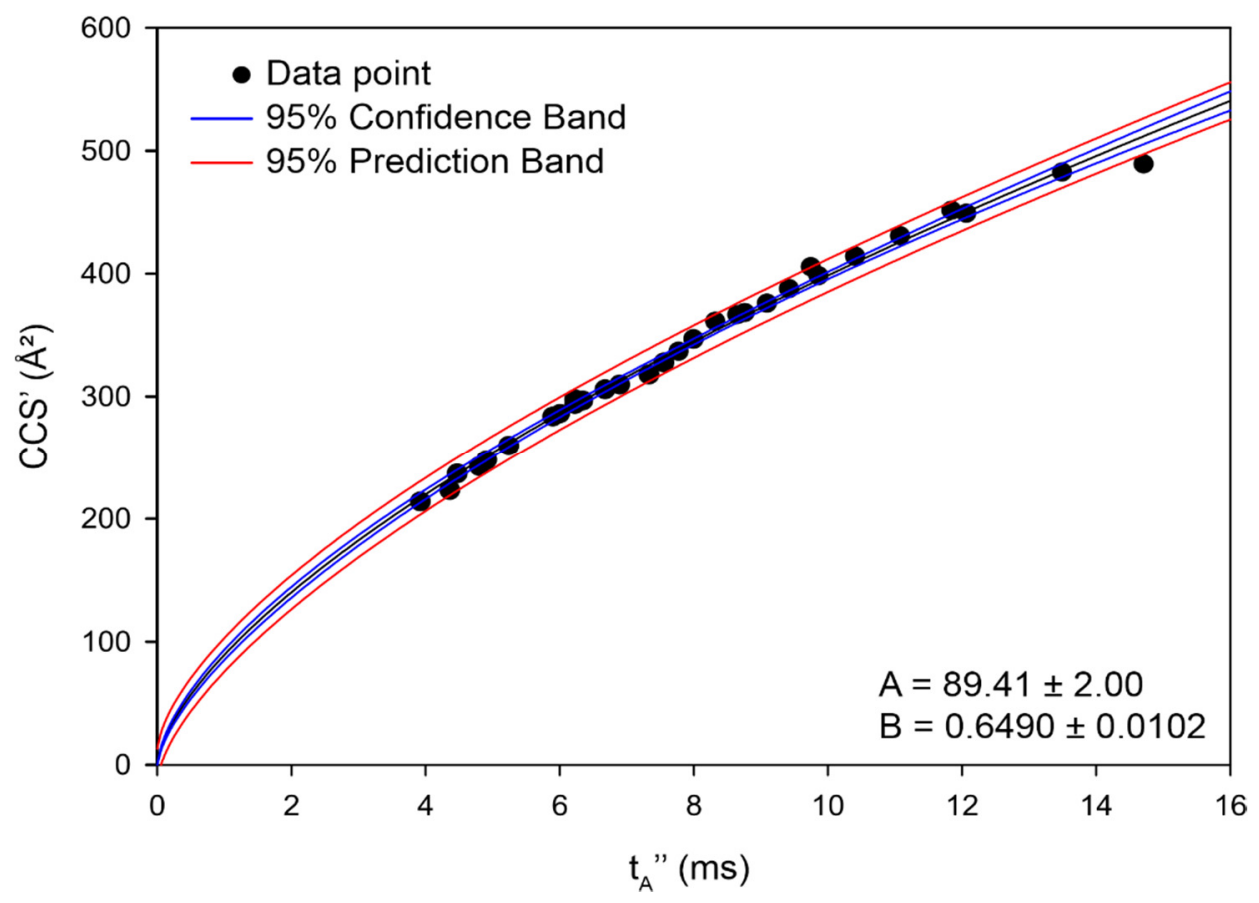

The corrected drift time $t_{d}{ }^{\prime}$ is calculated as $t_{d}-c \frac{\sqrt{\frac{m}{z}}}{1000}-\frac{L_{\text {transfer }}}{v_{\text {transfer }}}$, where $c$ is equal to $1.57, \mathrm{~m} / \mathrm{z}$ is the mass-to-charge ratio, $L_{\text {transfer }}$ is the length of the transfer cell $(130 \mathrm{~mm})$ and $v_{\text {transfer }}$ is the wave speed in the transfer cell (380 m.s $\mathrm{s}^{-1}$ in our case). Reported collision cross sections $\Omega$ are converted into $\Omega^{\prime}$ using equation $\Omega^{\prime}=\Omega \cdot \frac{\sqrt{\mu}}{z}$, where $\mu$ is the reduced mass. The fit relies on a power relationship $y=A \cdot x^{B}$. Using an IMS wave speed of $1000 \mathrm{~m} / \mathrm{s}$, a wave height of $40 \mathrm{~V}$ and a nitrogen pressure of 2.75 mbar in the mobility cell, we obtained the following parameters:

$$
\mathrm{A}=89.41 \pm 2.00 \text { and } \mathrm{B}=0,6490 \pm 0,0102
$$

The prediction error ( $\Omega$ interval defining $95 \%$ chance of finding the true value using the calibration curve, red bands) is $3.5 \%$, the confidence error ( $\Omega$ interval defining $95 \%$ chance of finding the value for repeated measurements of molecules belonging to the calibration data set, blue bands) is $1.1 \%$. 
Figure S2. Representation of the heme group and BS3 cross-linker and force field parametrization.

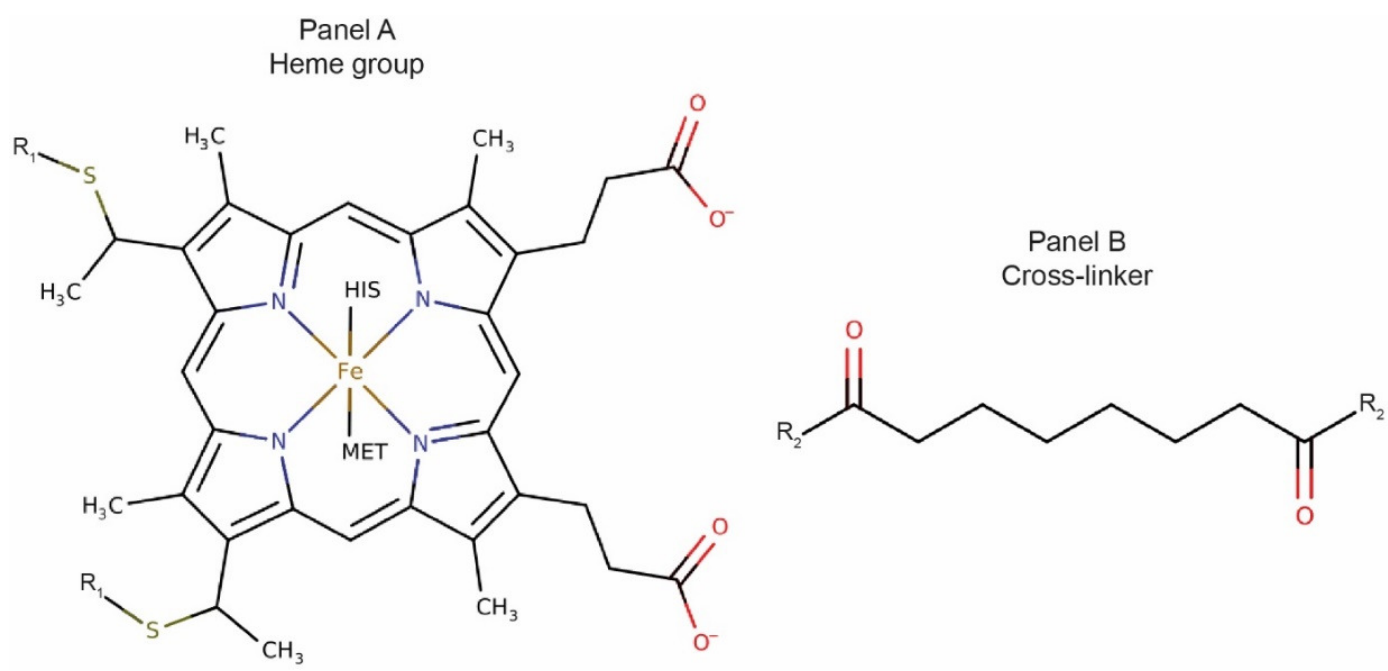

${ }^{a}$ Gattuso, H.; Duchanois, T.; Besancenot, V.; Barbieux, C.; Assfeld, X.; Becuwe, P.; Gros, P. C.; Grandemange, S.; Monari, A. Interaction of iron II complexes with B-DNA. Insights from molecular modeling, spectroscopy, and cellular biology, Front. Chem. 2015, 3, 1-12.

${ }^{\mathrm{b}}$ Charge-Transfer versus Charge-Separated Triplet Excited States of $\left[\operatorname{Re}^{\mathrm{I}}(\mathrm{dmp})(\mathrm{CO})_{3}(\operatorname{His} 124)(\operatorname{Trp} 122)\right]^{+}$in Water and in Modified Pseudomonas aeruginosa Azurin Protein, Chem. Eur. J. 2019, M Marazzi, H Gattuso, M Fumanal, C Daniel, A Monari. Chemistry-A European Journal, 25, 2519-2526.

To ensure accurate geometry optimization and charge distribution, the side chains of bound His and Met and of both bound Cys were included in the modeled system for the heme group and the N-hydroxysulfosuccinimide leaving groups of the linker were replaced with $-\mathrm{NHCH}_{3}$ groups. The two covalently linked Cys residues were first capped with $\mathrm{R}_{1}=-\mathrm{CH}_{3}$ groups (Figure S2, Panel A) and geometry optimization were performed for both molecules at he DFT/B3LYP level of theory with the LANL2DZ basis set for the heme residue and 6-31G* for the crosslinker. Partial atomic charges were computed at the same level of theory using the standard RESP procedure. Then, the $\mathrm{R}_{1}$ units were removed and their partial charges were redistributed on the heme group. Both bound and unbound force field parameters were extracted from the Amber14SB force field for bonds, angles and dihedrals. For parameters involving the iron atom, 
parameters were manually fitted to obtain reasonable geometry fluctuations around the optimized structure similarly to previous studies on octahedral environment around heavy metals such as Fe and Re. ${ }^{\mathrm{a}, \mathrm{b}}$

Similarly, the N-hydroxysulfosuccinimide leaving groups of the cross-linker were replaced with $\mathrm{R}_{2}=-\mathrm{NHCH}_{3}$ moities (Figure $\mathrm{S} 2$, Panel $\mathrm{B}$ ) for optimization and atomic charge calculations. They were subsequently removed and partial atomic charges were redistributed on all other atoms. Additionally, a new residue, characterized by the same canonical Amber force field parameters as the Lys residue, was defined in Amber libraries to allow the binding of cross-linkers. 
Figure S3. CL/ML products for $\beta$-lactoglobulin $(z=+9)$ and myoglobin $(z=+9)$. (a) $\beta$-lactoglobulin

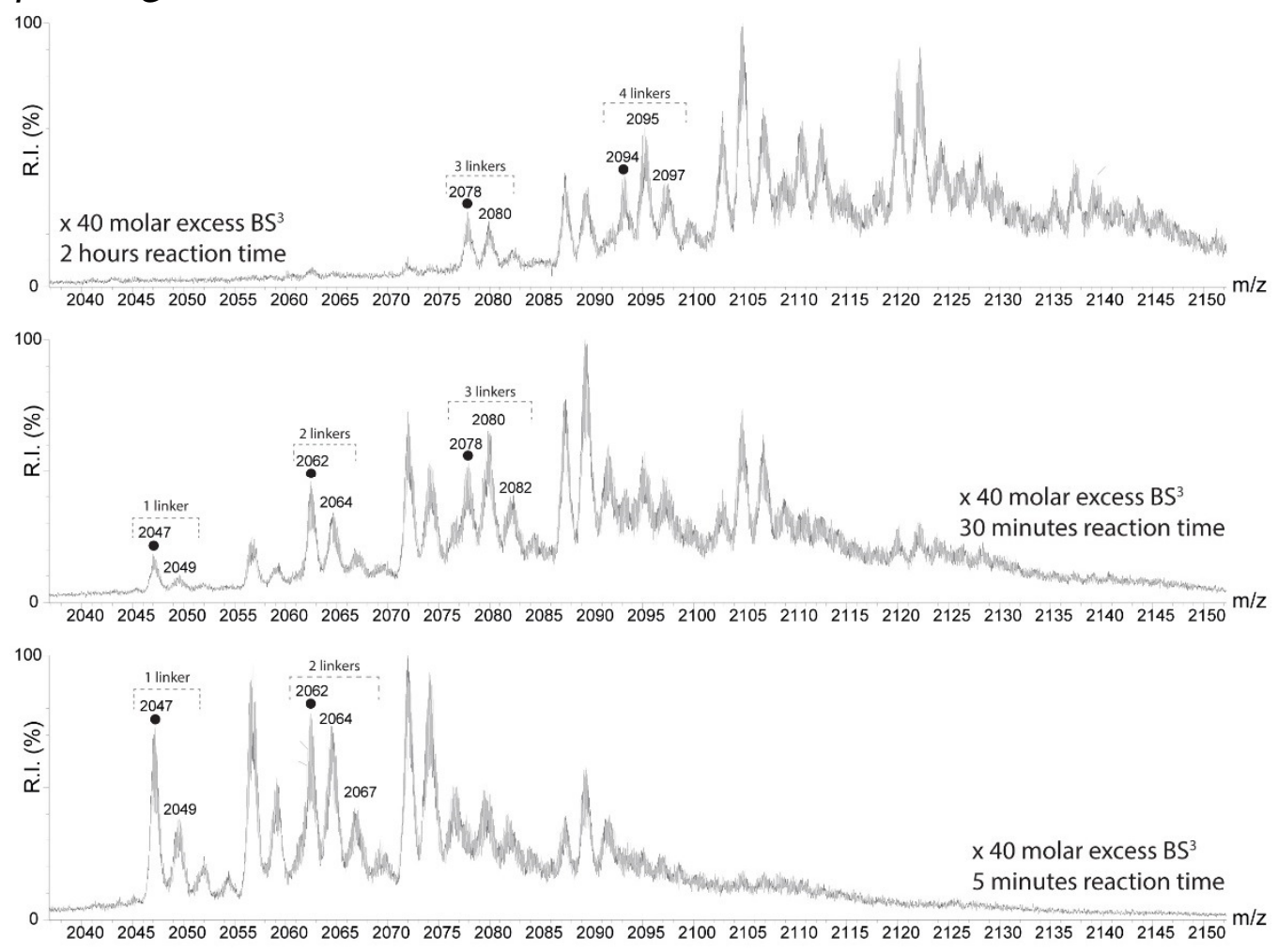

\section{(b) myoglobin}

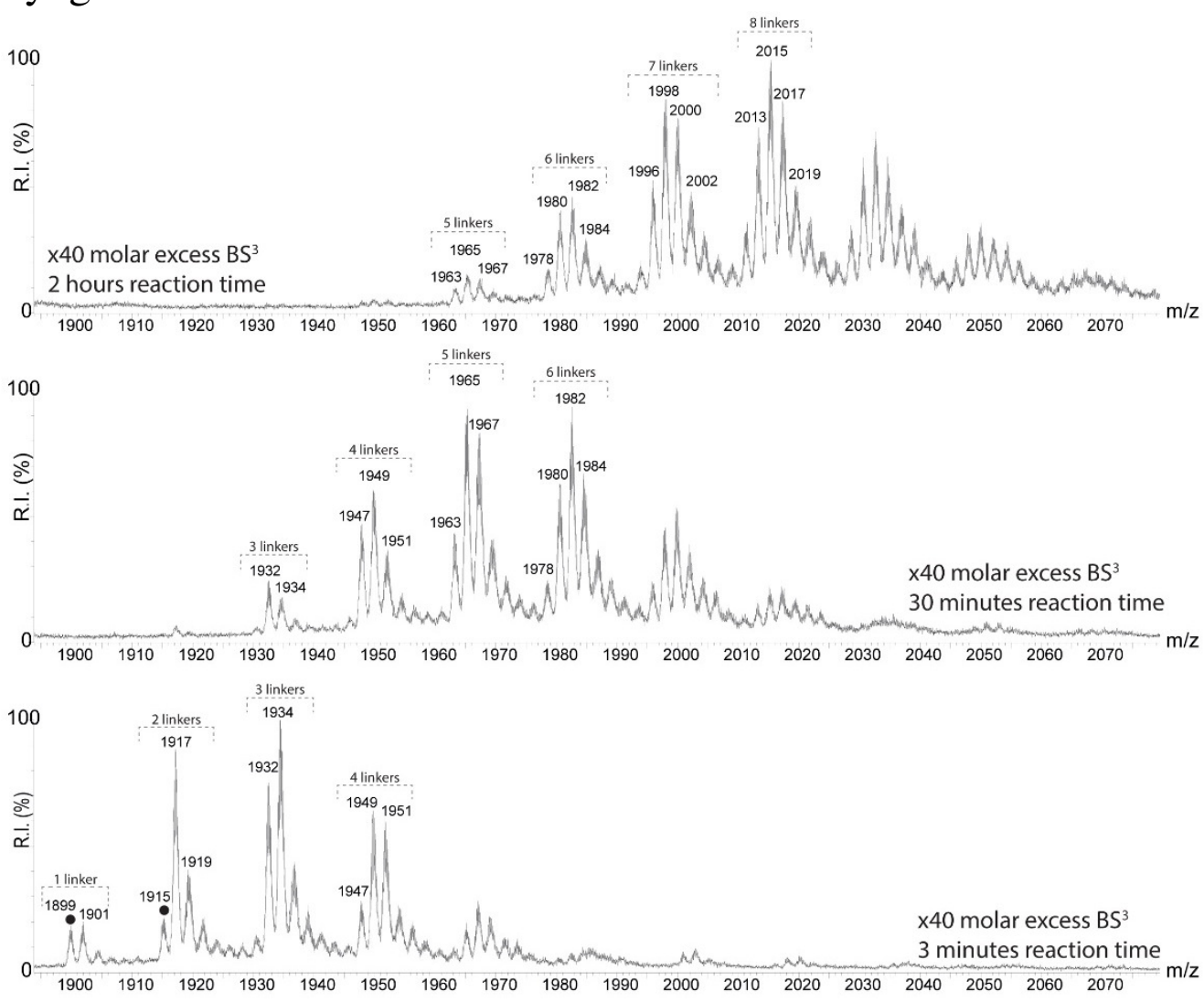

The black circles correspond to 100\% CL. Data were acquired in Q-TOF mode, IM off. 
Figure S4. CSDs of (non-)cross-linked $\beta$-lactoglobulin and myoglobin.

(a) $\beta$-lactoglobulin
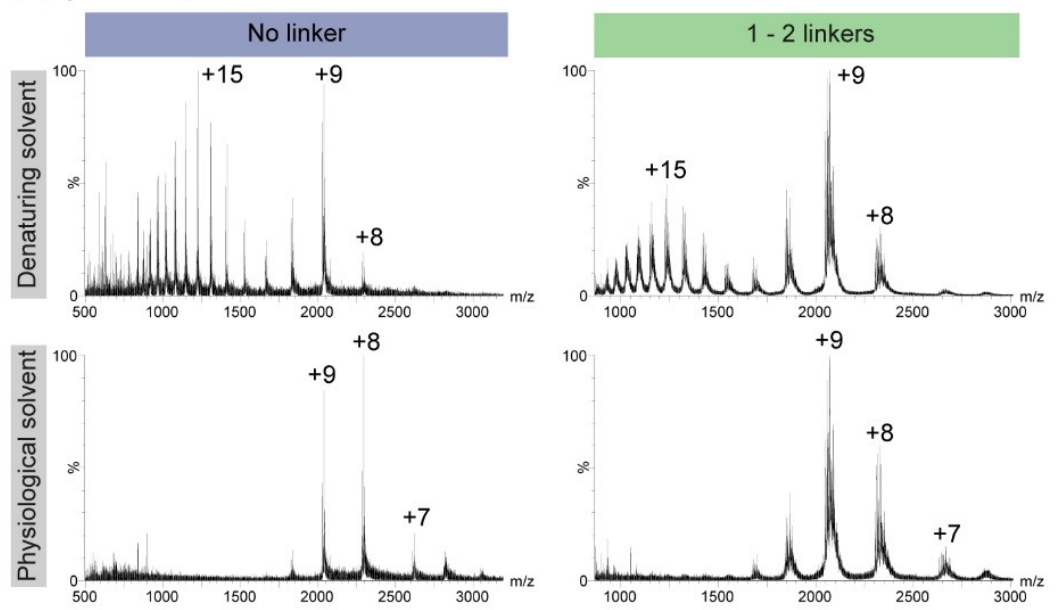

(b) Myoglobin
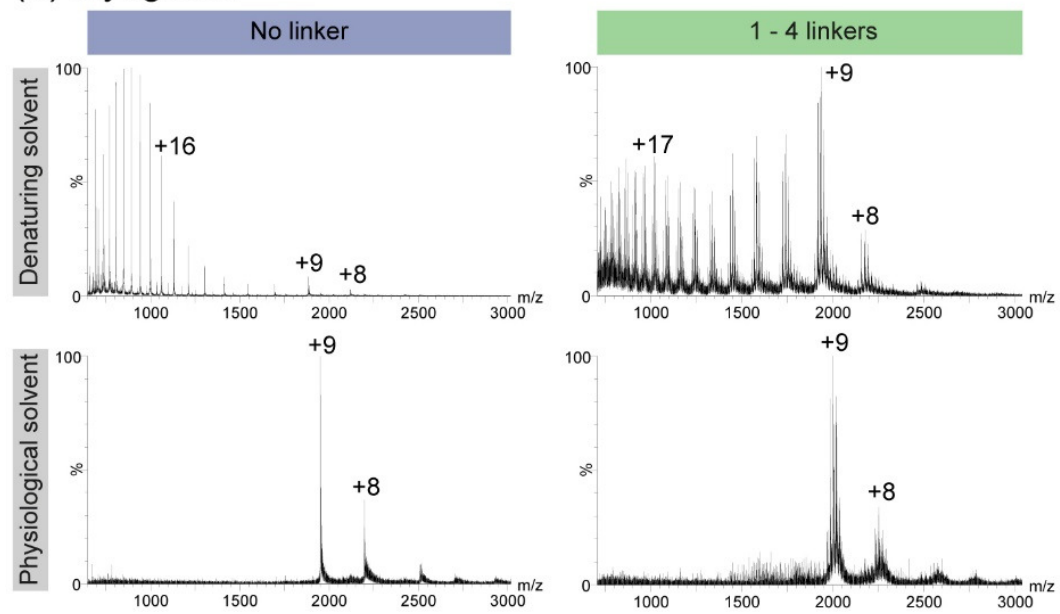
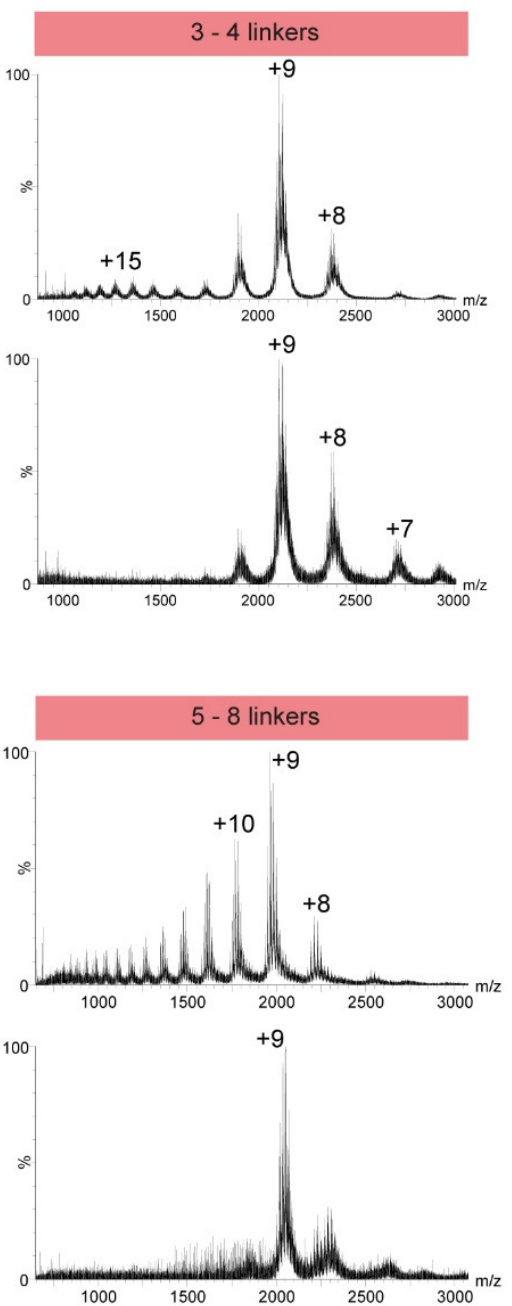

Data were acquired in Q-TOF mode, IM off mode. 
Figure S5. ${ }^{\mathrm{TW}} \mathrm{CCS}_{\mathrm{N} 2 \rightarrow \mathrm{He}}$ distributions of $\beta$-lactoglobulin $(z=+9)$ and myoglobin $(z=+9)$.

(a) $\beta$-lactoglobulin

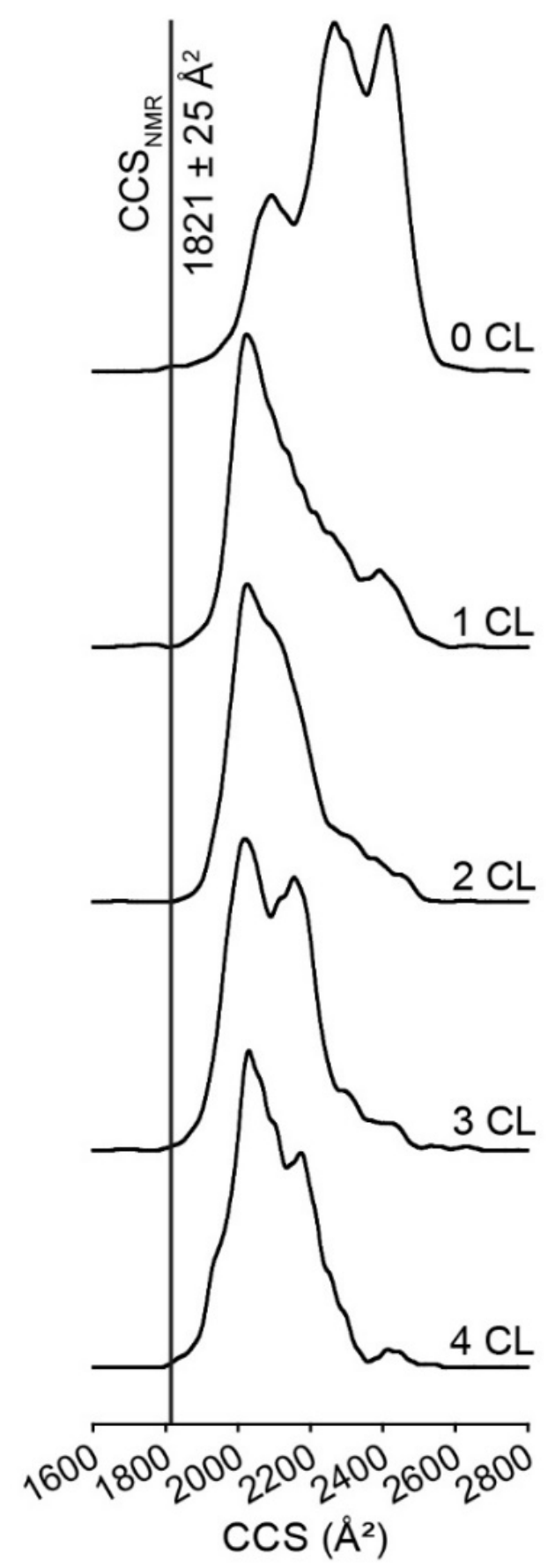

(b) Myoglobin

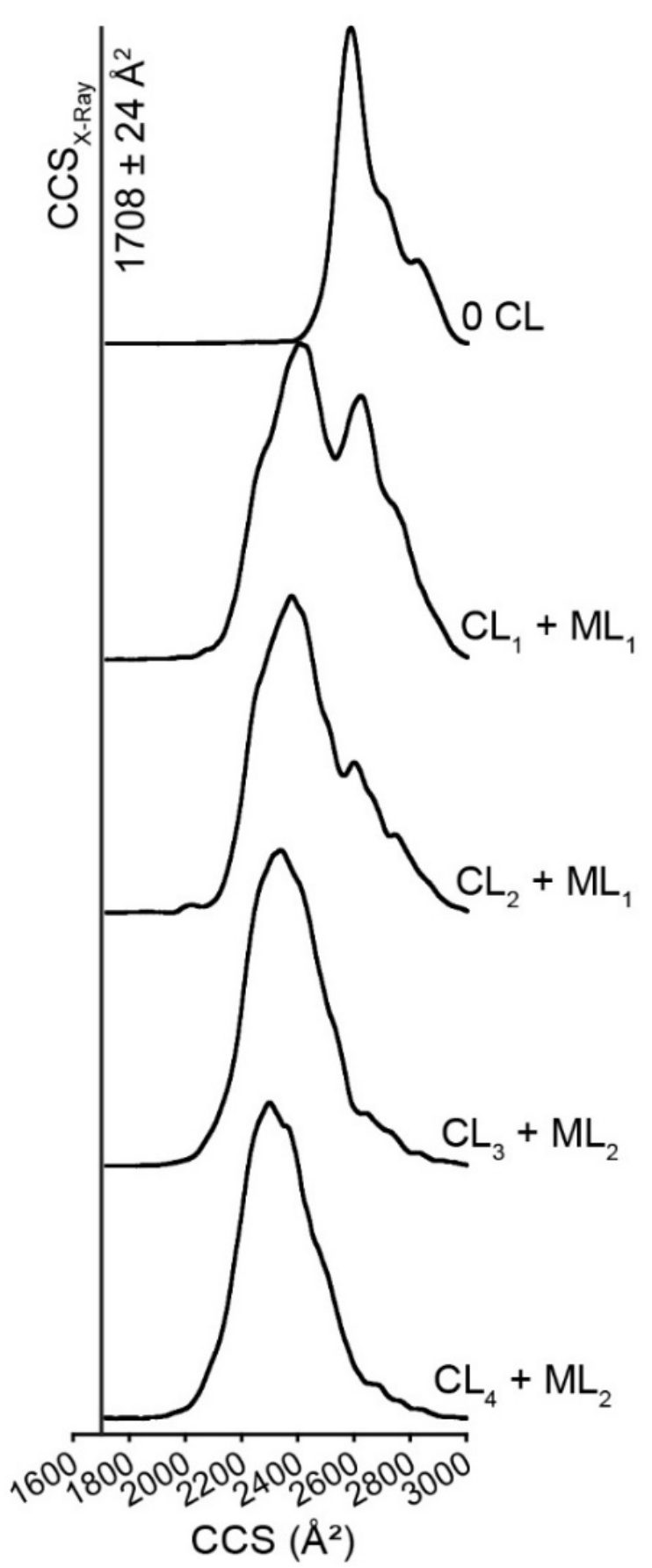

Ions are sprayed from physiological solvent (100:0 buffer:MeOH) and a trap bias voltage of 60 $\mathrm{V}$ is used. 
Figure S6. Positions of the $\mathrm{BS}^{3}$ linkers on the starting geometry of cytochrome $c$ used for MD.
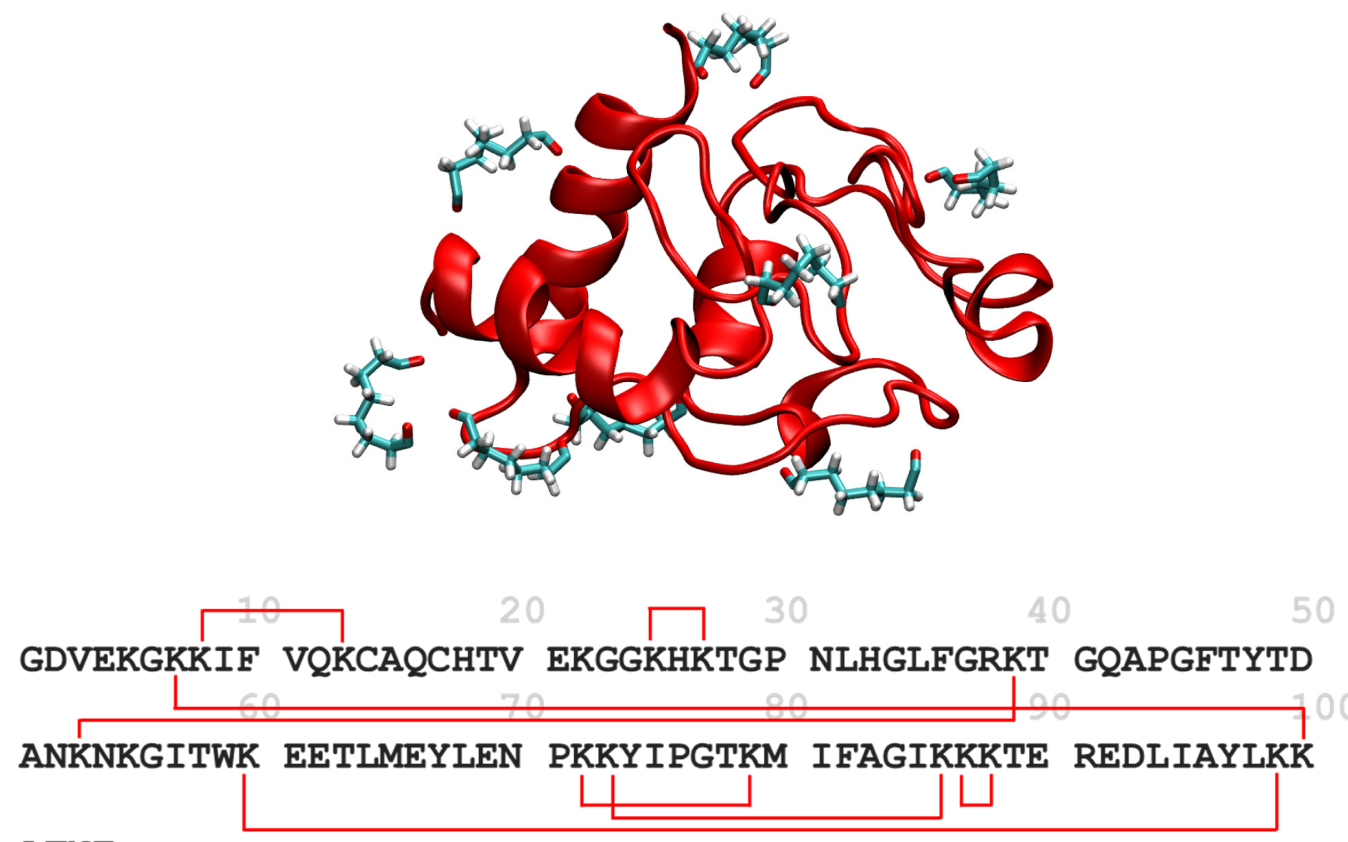

ATNE

Table S4. List of the reported BS3 cross-linked residues for cytochrome $c$.

\begin{tabular}{|c|c|}
\hline Cross-link & Reference \\
\hline K7 - K100 & $\mathrm{a}$ \\
\hline K13 - K8 & $\mathrm{b}, \mathrm{c}$ \\
\hline $\mathrm{K} 25-\mathrm{K} 27$ & $\mathrm{a}, \mathrm{b}, \mathrm{c}, \mathrm{d}, \mathrm{e}$ \\
\hline $\mathrm{K} 39-\mathrm{K} 53$ & $\mathrm{~b}, \mathrm{e}$ \\
\hline $\mathrm{K} 72-\mathrm{K} 79$ & $\mathrm{~b}$ \\
\hline $\mathrm{K} 86-\mathrm{K} 73$ & $\mathrm{~b}$ \\
\hline K87 - K88 & $\mathrm{e}$ \\
\hline K99 - K60 & Absence of steric constrains \\
\hline
\end{tabular}

${ }^{\text {a }}$ Xu, H.; Hsu, P.-H.; Zhang, L.; Tsai, M.-D.; Freitas, M. A., J. Proteome Res. 2010, 9, 3384-3393.

b Pearson, K. M.; Pannell, L. K.; Fales, H. M., Rapid Commun. Mass Spectrom. 2002, 16, 149-159.

c Young, J. L.; Lackner, L. L.; Nunnari, J. M.; Phinney, B. S., J. Proteome Res. 2007, 6, 3908-3917.

d Dihazi, G. H.; Sinz, A., Rapid Commun. Mass Spectrom. 2003, 17, 2005-2014.

e Seebacher, J.; Mallick, P.; Zhang, N.; Eddes, J. S.; Aebersold, R.; Gelb, M. H., J. Proteome Res. 2006, 5, 22702282. 
Figure S7. Positions of the electric charges on the initial geometry of cytochrome $c$ used for MD.
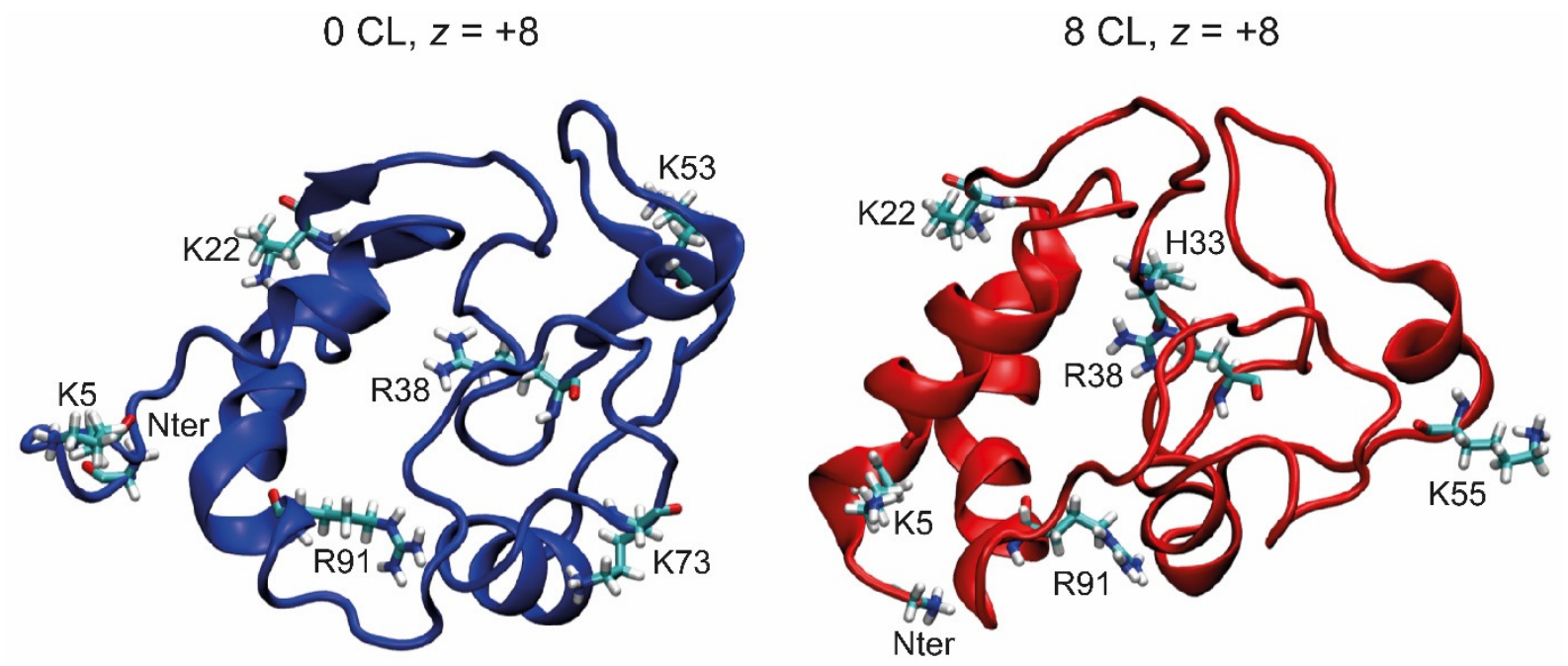

Table S5. List of the positions of the electric charges on the initial geometry of cytochrome $c$ used for MD.

\begin{tabular}{|c|c|}
\hline 0 CL & $\mathbf{8 ~ C L}$ \\
\hline $\mathrm{N}_{\text {ter }}$ & $\mathrm{N}_{\text {ter }}$ \\
\hline K5 & K5 \\
\hline K22 & K22 \\
\hline K53 & K55 \\
\hline K73 & H33 \\
\hline R38 & R38 \\
\hline R91 & R91 \\
\hline Heme $(+1)$ & Heme $(+1)$ \\
\hline
\end{tabular}


Figure S8. ${ }^{\mathrm{TW}} \mathrm{CCS}_{\mathrm{N} 2 \rightarrow \mathrm{He}}$ distributions of cytochrome $c$ carrying from $0 \mathrm{ML}$ to 3 ML.

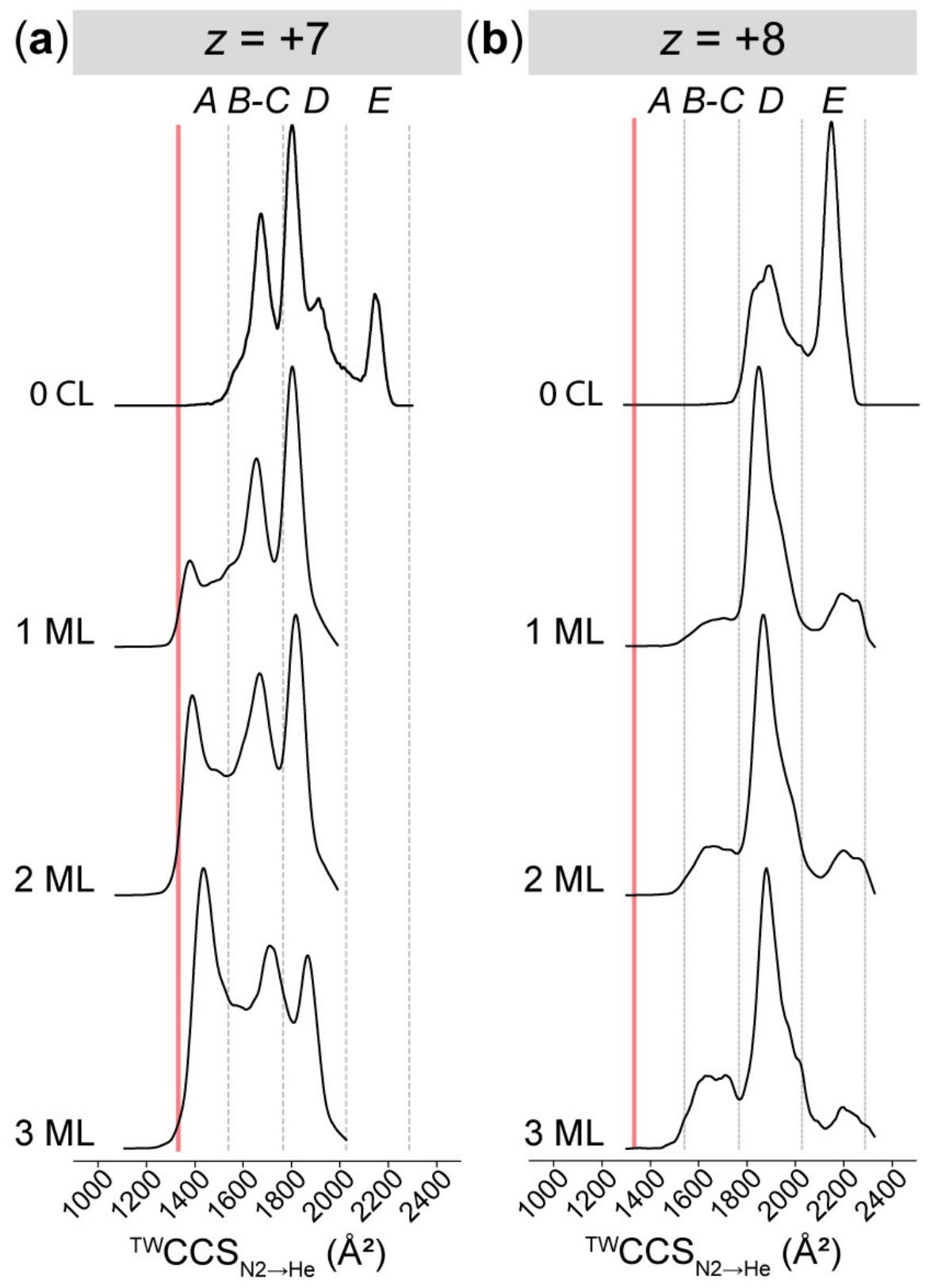

Ions are sprayed from physiological solvent (100:0 buffer:MeOH) and a trap bias voltage of 60 $\mathrm{V}$ is used. 